\title{
Ophthalmic Graves's disease: natural history and detailed thyroid function studies
}

\author{
C S TENG, PETER P B YEO
}

British Medical fournal, 1977, 1, 273-275

\section{Summary}

Of 27 patients with ophthalmic Graves's disease (OGD) who had been clinically euthyroid three years previously, one became clinically hyperthyroid and seven overtly hypothyroid. Improvement in eye signs was associated with a return to normal of thyroidal suppression by triiodothyronine (T3) and of the response of thyroidstimulating hormone (TSH) to thyrotrophin-releasing hormone (TRH). Of a further 30 patients with OGD who had not been studied previously, three were overtly hypothyroid.

Of the combined series, 46 patients were euthyroid, $18(40 \%)$ of whom had an impaired or absent TSH response to TRH, and $3(6.7 \%)$ an exaggerated response. Eleven out of 37 patients $(29.7 \%)$ had abnormal results in the T3 suppression test.

There was a significant correlation between thyroidal suppression by T3 and the TSH response to TRH. Total serum concentrations of both $T 3$ and thyroxine (T4) were closely correlated with $T 3$ suppressibility and TRH responsiveness. Free T4 and T3 (fT3) concentrations were normal in all but three patients, in whom raised $f T 3$ was accompanied by abnormal TSH responses and thyroidal suppression.

University of Newcastle upon Tyne, Department of Medicine (Endocrine Unit), Royal Victoria Infirmary, Newcastle upon Tyne NE1 4LP

C S TENG, MB, MRCP, clinical research fellow (now lecturer in medicine, University of Hong Kong)

P P B YEO, MB, MRCP, senior research associate

The presence of normal free thyroid hormone concentrations in patients with impaired or absent TSH responses to TRH is interesting and challenges the concept that free thyroid hormones are the major controlling factors in the feedback control of TSH.

\section{Introduction}

Rundle and Wilson' used the term "ophthalmic type of Graves's disease" to describe the ocular changes of Graves's disease occurring in the absence of goitre or hyperthyroidism. Hall et $a l^{2}$ expanded the definition to include thyroid enlargement provided that the patient was euthyroid and had no history of hyperthyroidism. Now, however, owing to the description of ophthalmopathy characteristic of Graves's disease in Hashimoto's thyroiditis, ${ }^{3}$ patients with clinical or biochemical evidence of hypothyroidism are included. ${ }^{4}$

The natural history of ophthalmic Graves's disease (OGD) remains to be established. In 1975 we reviewed clinically and biochemically a group of patients with OGD who had been clinically euthyroid in $1972 . .^{4}$ Our objective was to define the disturbance of thyroid hormone metabolism by measuring the total and free thyroid hormone concentrations and the thyrotrophin (TSH) response to thyrotrophin-releasing hormone (TRH) and carrying out a triiodothyronine suppression (T3S) test.

\section{Patients and methods}

We reviewed 27 out of 34 patients with OGD who had been studied in $1972 . .^{4}$ Of the remaining seven patients, four had died of unrelated illnesses and three could not be traced. A further 30 patients attending the endocrine unit were added to the series, making a total of 57 patients.

Ocular changes were assessed clinically and scored by the scheme 
adopted by the American Thyroid Association, ${ }^{5}$ and an ophthalmopathy index was derived for each patient. ${ }^{6}$ The progression of eye changes was assessed from the outpatient records and from the patients' own observations. Thyroid function was assessed clinically and by the following methods: measurement of serum protein-bound iodine (PBI ; AutoAnalyzer method 56); residual thyroid-hormone binding test (Thyopac-3); calculation of free thyroxine index (FTI) from the previous two results ${ }^{7}$; radioimmunoassays of triiodothyronine (T3), ${ }^{*}$ thyroxine (T4), ${ }^{9}$ free T3 (fT3), ${ }^{10}$ and free T4 (fT4) ${ }^{10}$; and the TRH test. ${ }^{11}$ The TSH response to TRH was recorded as normal, exaggerated, impaired, or absent according to criteria previously described. ${ }^{12}$ The T3S test was performed by measuring the six-hour thyroidal uptake of ${ }^{131}$ I before and seven days after the daily administration of $120 \mathrm{\mu g}$ of T3. Reasons for not performing TRH and T3S tests in some patients were treatment with thyroxine (10 patients), coexisting heart disease, and social inconvenience. Antibodies to thyroglobulin were detected by the tanned-red-cell technique, and thyroid cytoplasmic antibodies by complement fixation as described in the World Health Organisation manual for autoimmune serology.

\section{Results}

\section{CLINICAL FEATURES}

Of the 27 patients first studied in 1972, seven had become overtly hypothyroid and were receiving thyroxine replacement, and one had developed hyperthyroidism after 12 years of eye trouble and was therefore excluded. Three of the 30 additional patients were clinically hypothyroid. Thus 46 patients were clinically euthyroid. Of the 56 patients included in the study, 41 were women aged 29-73 years (mean age 52) and 15 men aged 41-75 years (mean age 62). Ten patients had a family history of thyroid disease. Goitre was found in 16 patients, while in another 12 the thyroid was just palpable. The following eye signs were noted: exophthalmos (23 cases; 14 unilateral, 9 bilateral); lid retraction (14;12 unilateral, 2 bilateral); periorbital swelling ( 45 ; all bilateral); ophthalmoplegia (15;3 unilateral, 12 bilateral); and chemosis ( $3 ; 2$ unilateral, 1 bilateral).

Seven patients showed progressive deterioration of their eye signs, which needed treatment including steriods or orbital irradiation ${ }^{13}$; in

TABLE I-Change in eye signs in patients with OGD

\begin{tabular}{l|c|c|c}
\hline & $\begin{array}{c}\text { No of } \\
\text { patients }\end{array}$ & $\begin{array}{c}\text { Mean } \\
\text { ophthalmopathy } \\
\text { index }\end{array}$ & $\begin{array}{c}\text { Mean duration } \\
\text { of symptoms } \\
\text { (years) } \pm \text { SD }\end{array}$ \\
\hline $\begin{array}{l}\text { Eye signs improved } \\
\text { Eye signs unchanged }\end{array}$ & $\begin{array}{l}37 \\
\text { Eye signs deteriorated }\end{array}$ & $\begin{array}{l}1 \cdot 11 \\
2 \cdot 00\end{array}$ & $\begin{array}{c}6 \cdot 19 \pm 3 \cdot 33 \\
5 \cdot 65 \pm 3.87 \\
2 \cdot 10 \pm 1 \cdot 45\end{array}$
\end{tabular}

TABLE II-Mean thyroid function values $( \pm S D)$ in 19 patients with euthyroid $O G D$ in 1972 and 1975

\begin{tabular}{|c|c|c|c|}
\hline & 1972 & 1975 & $\mathbf{P}$ \\
\hline $\begin{array}{l}\text { PBI (nmol/1) (normal } 315-630) \\
\text { FTI (normal 270-680) } \\
\text { T3 (nmol/1) (normal } 1 \cdot 0-2 \cdot 6) \\
\text { Rise in TSH 20 min after TRH (mU/1) } \\
\text { (normals: men 4.2-16.1; women } \\
5 \cdot 9-18 \cdot 2) \\
\% \text { fall in } 232 \text { I uptake after T3 } \\
\text { (normal } \geqslant 50 \text { ) }\end{array}$ & $\begin{array}{c}522 \pm 121 \\
478 \pm 101 \\
2 \cdot 56 \pm 0.63 \\
4 \cdot 83 \pm 5 \cdot 06 \\
41 \cdot 51 \pm 26.66\end{array}$ & \begin{tabular}{|l|l}
$523 \pm 95$ \\
$475 \pm 83$ \\
$1 \cdot 93 \pm 0 \cdot 56$ \\
$6 \cdot 51 \pm 4 \cdot 8$ \\
\\
$60 \cdot 16 \pm 27 \cdot 88$
\end{tabular} & $\begin{array}{l}\text { NS } \\
\text { NS } \\
0.0025 \\
0.025 \\
0.005\end{array}$ \\
\hline
\end{tabular}

NS = Not significant

Conversion: SI to traditional units-PBI: $1 \mathrm{nmol} / 1 \approx 0.013 \mu \mathrm{g} / 100 \mathrm{ml}$. T3: $1 \mathrm{nmol} / 1$ $\approx 0.65 \mathrm{ng} / \mathrm{ml}$.
37 patients spontaneous improvement occurred, and 12 patients remained unchanged (table $\mathrm{I}$ ).

CHANGES IN EYE SIGNS AND THYROID FUNCTION BETWEEN 1972 AND 1975

Six of the seven patients who developed overt hypothyroidism between 1972 and 1975 had exaggerated responses in TRH tests in 1972 (four with raised basal TSH concentrations), while the remaining one had TSH responses that progressed from impaired to normal in 1972 and finally to exaggerated in 1975 . The eye signs deteriorated in one patient during the transition from subclinical to clinical hypothyroidism but improved with thyroxine and concomitant steroid treatment by mouth. The eye signs in four of the six remaining patients improved with thyroid hormone replacement, while two patients reported no change. (The one patient who developed clinical hyperthyroidism had an absent TSH response to TRH previously; the eye signs were unchanged during the intervening period.)

Among the 19 euthyroid patients the important changes in the TSH response to TRH (table II)-namely, the reversion from absent or impaired responses to normal responses-were associated with improvement in the ocular manifestations. The greater suppressibility of thyroid radioiodine uptake in 1975 (table II) was similarly related to the eye signs. The titre of cytoplasmic antibodies tended to increase with time, suggesting, perhaps, progression to a more severe degree of autoimmune thyroiditis; nevertheless, the total number of patients with thyroid antibodies remained the same from 1972 to 1975 . Of all 56 patients studied, 29 had thyroglobulin antibodies (titre $1 / 20$ or more) or cytoplasmic antibodies (titre $1 / 64$ or more) or both. Of the 10 hypothyroid patients, eight had strong titres of cytoplasmic antibodies ( $1 / 256$ to $1 / 1600)$, one a weak titre of thyroglobulin antibody $(1 / 80)$, and one no detectable thyroid antibodies.

\section{SERUM TOTAL T3 AND T4, TSH RESPONSE, AND T3 SUPPRESSIBILITY}

Of the 46 clinically euthyroid patients, 45 were tested with TRH: $18(40 \%)$ had an impaired or absent $\mathrm{TSH}$ response, and $3(6.7 \%)$ one with subclinical hypothyroidism and a raised basal TSH concentration-an exaggerated response (table III). The T3S test was performed on 37 of the 46 patients (one of the 37 was not tested with $\mathrm{TRH}) ; 11(29.7 \%)$ had abnormal results. There was a significant correlation between $\mathrm{T} 3$ suppressibility and $\mathrm{TSH}$ response $(r=0.43$, $\mathrm{P}<0.01$ ). Total serum concentrations of both $\mathrm{T} 3$ and $\mathrm{T} 4$ correlated well with T3 suppressibility and $\mathrm{TSH}$ response $(\mathrm{T} 3 / \mathrm{T} 3 \mathrm{~S}: \mathrm{r}=0.39$ $\mathrm{P}<0.05 ; \mathrm{T} 3 / \mathrm{TSH}: \mathrm{r}=0.62, \mathrm{P}<0.001 ; \mathrm{T} 4 / \mathrm{T} 3 \mathrm{~S}: \mathrm{r}=0.38, \mathrm{P}<0.05$; T4/TSH: $r=0.5, P<0.001)$.

\section{SERUM fT3 AND FT4, TSH RESPONSE, AND T3 SUPPRESSIBILITY}

Serum fT 3 and fT 4 were studied in 37 euthyroid patients. Fifteen had normal responses to T3S and TRH, and 22 an impaired or absent TSH response or T3 non-suppressibility or both. Serum fT3 was raised in three patients in the second group $(17.4,19.4$, and 22.4 $\mathrm{pmol} / 1(11 \cdot 3,12 \cdot 6$, and $14.6 \mathrm{pg} / \mathrm{ml}$ ) respectively) (normal $4 \cdot 5-15 \cdot 7$ $\mathrm{pmol} / \mathrm{l} ; 2 \cdot 9-10 \cdot 2 \mathrm{pg} / \mathrm{ml}) .{ }^{10}$ The remaining patients in both groups had fT3 and fT4 concentrations within the normal ranges with no significant differences between the means in both groups. For the overall population in the two groups, fT3 and fT4 did not show significant correlations with $\mathrm{T} 3$ suppressibility and $\mathrm{TSH}$ response (fT3/T3S: $r=0.343, \mathrm{P}>0.05$; fT3/TSH: $\mathrm{r}=0.066, \mathrm{P}>0.1$; fT4/T3S : $r=0.082, \mathrm{P}>0.1 ; \mathrm{fT} 4 / \mathrm{TSH}: \mathrm{r}=0.136, \mathrm{P}>0.1)$.

TABLE III-Mean thyroid function values $( \pm S D$ ) in 45 patients with euthyroid OGD in 1975. (Only 36 of these patients were tested for both TSH response to TRH and percentage fall in ${ }^{131}$ I uptake after T3)

\begin{tabular}{|c|c|c|c|c|c|}
\hline & $\underset{(\mathrm{nmol} / \mathbf{l})}{\mathrm{PBI}}$ & FTI & $\begin{array}{c}\mathrm{T3} \\
(\mathrm{nmol} / \mathrm{l})\end{array}$ & $\begin{array}{c}\mathrm{T4} \\
(\mathrm{nmol} / 1)^{*}\end{array}$ & 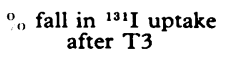 \\
\hline $\begin{array}{l}\text { Absent TSH response }(n=4) \\
\text { Impaired TSH response }(n=14) \\
\text { Normal TSH response }(n=24) \\
\text { Exaggerated TSH response }(n=3)\end{array}$ & $\begin{array}{l}540 \pm 83 \\
524 \pm 85 \\
489 \pm 93 \\
358 \pm 78\end{array}$ & $\begin{array}{l}464 \pm 63 \\
476 \pm 81 \\
439 \pm 76 \\
339 \pm 84\end{array}$ & $\begin{array}{l}2.34 \pm 0.39 \\
2 \cdot 03 \pm 0.47 \\
1.86 \pm 0.34 \\
1.09 \pm 0.52\end{array}$ & $\begin{array}{l}131 \pm 8 \\
129 \pm 23 \\
117 \pm 32 \\
92 \pm 43\end{array}$ & $\begin{array}{l}36 \cdot 33 \pm 40 \cdot 84(n=4) \\
55 \cdot 0 \pm 22 \cdot 26(n=8) \\
62 \cdot 47 \pm 27 \cdot 57(n=21) \\
94 \cdot 74 \pm 0 \cdot 88(n=3)\end{array}$ \\
\hline
\end{tabular}




\section{Discussion}

It is well recognised that some euthyroid patients with OGD have abnormalities of thyroid function, including exaggerated, impaired, or absent responses of $\mathrm{TSH}$ to $\mathrm{TRH},{ }^{4}$ lack of suppression of thyroidal radioiodine uptake by $\mathrm{T} 3,{ }^{2+}$ and an increased prevalence of thyroid autoantibody, ${ }^{2}{ }^{4}$ as shown again in this study. Liddle et al ${ }^{14}$ suggested that limited thyroidal reserve with inability to respond to thyroid-stimulating agents was responsible for patients with OGD not becoming hyperthyroid, although this was subsequently challenged by Hall et $a l,{ }^{2}$ who thought that it was valid for only a few patients. Only one of our 27 patients first studied in 1972 progressed to frank hyperthyroidism, which confirms the impression that only a few of these patients develop clinical hyperthyroidism. ${ }^{4}$ Overt hypothyrodism, on the other hand, occurred more often in this study, presumably as a result of autoimmune thyroid disease, as evidenced by the presence of thyroid antibodies. The rising titres of thyroid antibodies with time was similar to that observed in a non-hospital population. ${ }^{15}$ Hall et al ${ }^{2}$ reported that a third of their patients with OGD had high titres of thyroglobulin or complement-fixing antibodies or both, similar to those in Hashimoto's disease; in addition the frequency of high titres of thyroglobulin antibodies was greater in patients with OGD than in thyrotoxic patients with Graves's disease. These observations were confirmed by Ormston et al. ${ }^{4}$ Graves's ophthalmopathy has also been described in 10 patients with histologically proved Hashimoto's thyroiditis. ${ }^{3}$ The improvement in eye signs associated with a return to normal of T3S or TSH response or both is interesting and suggests a relation between the pathogenesis of the ocular manifestations and the degree of thyroid autonomy in OGD. The possibility that the concentration of circulating thyroid hormones may influence the activity of established eye signs cannot be excluded.

We have confirmed the finding ${ }^{4}$ that euthyroid patients with OGD who have impaired or absent TRH responsiveness or failure of thyroidal suppression by $\mathrm{T} 3$ or both have thyroidfunction values that, although within "normal" ranges, tend to approach the hyperthyroid level, especially as regards serum total T3. The serum free thyroid hormones, however, were not examined previously. Interestingly, three of our 22 patients had raised fT 3 but normal fT4 and total hormone levels. The importance of this finding remains to be established. Serum fT 3 and fT 4 concentrations would probably be expected to be within normal ranges in patients with normal T3S and TSH responses. The presence of normal free thyroid hormone concentrations, however, in patients with impaired or absent
TSH responses and thyroid non-suppressibility challenges the concept that free thyroid hormones are the sole physiologically active moieties in the feedback control of TSH. The precise bases for these abnormal results in OGD therefore remain to be established, although failure of suppression of thyroidal ${ }^{131}$ I uptake by $\mathrm{T} 3$ implies that the thyroid-trapping process is controlled by a mechanism other than $\mathrm{TSH}$. The role of thyroid-stimulating immunoglobulins in the control of thyroid function in patients with OGD is discussed elsewhere. ${ }^{16}$

We are indebted to Professor R Hall, Dr D C Evered, and Dr F Clark for guidance and supervision during this study and for invaluable criticism of this paper. We thank Dr T Bird, department of haematology, Newcastle General Hospital, for the thyroid antibody determinations, and Mr B Clayton, department of medical physics, Royal Victoria Infirmary, for the radioiodine uptake tests. Part of this study was carried out during the tenure of a Nuffield Foundation Research Fellowship in endocrinology by PPBY; it is a pleasure to acknowledge the financial support of the foundation. The work will form part of an MD dissertation to be submitted to the University of Singapore. The study was also sunported by grants from the scientific and research committee of the Newcastle Area Health Authority (Teaching) and the Wellcome Foundation. We are grateful for the gifts of T4 antisera and high-specific-activity T3 from Dr G Smith, of the Radiochemical Centre, Amersham, and the excellent secretarial help of Mrs M Shepherd.

Requests for reprints should be sent to Dr P P B Yeo.

\section{References}

${ }^{1}$ Rundle, F E, and Wilson, C W, Lancet, 1945, 1, 51.

2 Hall, R, et al, Lancet, 1970, 1, 375.

3 Wyse, E P, et al, fournal of Clinical Endocrinology and Metabolism, 1968, 28, 982 .

4 Ormston, B J, et al, Clinical Endocrinology, 1973, 2, 369.

${ }^{5}$ Werner, S C, Fournal of Clinical Endocrinology and Metabolism, 1969, 29, 982 .

${ }^{6}$ Donaldson, S S, Bagshaw, M A, and Kriss, J P, fournal of Clinical Endocrinology and Metabolism, 1973, 37, 276.

${ }^{7}$ Clark, F, and Brown, H J, British Medical fournal, 1970, 1, 713.

${ }^{8}$ Hesch, R D, and Evered, D C, British Medical fournal, 1973, 1, 645.

${ }^{9}$ Evered, D C, et al, fournal of Clinical Pathology. In press.

${ }^{10}$ Yeo, P P B, Lewis, M, and Evered, D C, Clinical Endocrinology. In press.

11 Ormston, B J, et al, Lancet, 1971, 2, 10.

12 Hall, R, et al, Lancet, 1972, 1, 759.

13 Teng, C S, et al, Clinical Endocrinology. In press.

${ }^{14}$ Liddle, G W, Heyssel, R M, and McKenzie, J M, American fournal of Medicine, 1965, 39, 845.

${ }^{15}$ Khangure, M S, et al, Clinical Endocrinology. In press.

16 Teng, C S, et al, Clinical Endocrinology. In press.

(Accepted 7 October 1.976)
ONE HUNDRED YEARS AGO Initiated in midwifery by my late lamented friend Dr Edward Rigby, I was early taught the importance of the "binder" as a means of preventing post partum haemorrhage; and through a period of nearly thirty-three years, during greater part of which I have had a very extensive midwifery practice, I have only had one fatal case in my own practice.

In every case, I myself carefully bandaged the patient as tightly as possible with a shawl or large towel, in which I generally wrapped a book to form a pad over the uterus, with the best results, though I had then sometimes to deal with cases of haemorrhage.

In the year 1861, however, I was engaged to attend one of the largest women I ever saw. She was tall and immensely stout. The labour was natural, but rather tedious; and, after it was over, violent haemorrhage set in. Here any ordinary binder was useless; and to grasp the uterus through the parietes was impossible, from the immense quantity of fat on the wall of the abdomen. I had the advantage of the advice of my old friend Mr S D Fereday, and all the means which we could devise were used without effect. We watched her for some hours, a certain quantity of draining going on in spite of our efforts; and we anticipated a certainly fatal issue. Where art had failed, however, nature came to her assistance, and she ultimately recovered.

In the following year, I was again asked to attend her, and was called to see her one Sunday morning. I had a most lively recollection of her last labour and a firm reliance on the binder, and was determined, if possible, to bring one to bear on her huge abdomen; so I went to a saddler who lived near, and there extemporised a binder. It consisted of an oval piece of the strongest "butt leather" he had, ten inches long by eight wide, to each side of which a strong strap (nearly as strong as stirrup-straps) with buckle was attached. With this I was able to attain some degree of pressure. Suffice it to say the labour went on well and no flooding took place.

For some time afterwards, I took my "binder" with me only when I had to attend stout persons; but I soon found that the comfort of it was so great and the advantages so signal, that I began to take it with me to every patient I attended, and have continued to do so for the last eight or nine years; and during that period I have not had a single case of haemorrhage that has given me the slightest anxiety.

This is the practical fact I wish to bring forward: I apply the bandage gently before the child is born. I make the nurse press on the pad during the expulsion of the child. I then tighten the bandage pretty firmly; and, after the expulsion of the placenta, which is rarely long delayed, I again tighten it as firmly as the patient can comfortably bear. It is very rarely necessary to do more; but if the pains be sluggish or infrequent, and if pressure by the binder do not increase them, I give a dose of ergot just before the child is born. (British Medical fournal, 1877.) 